\title{
Accelerator mass spectrometry for quantitative in vivo tracing
}

\author{
John S. Vogel \\ University of California, Livermore, CA, USA \\ BioTechniques 38:S25-S29 (June 2005)
}

Accelerator mass spectrometry (AMS) counts individual rare, usually radio-, isotopes such as radiocarbon at high efficiency and specificity in milligram-sized samples. AMS traces very low chemical doses (micrograms) and radiative doses (100 Bq) of isotope-labeled compounds in animal models and directly in humans for pharmaceutical, nutritional, or toxicological research. Absorption, metabolism, distribution, binding, and elimination are all quantifiable with high precision after appropriate sample definition.

\section{INTRODUCTION}

Stable isotope ratio mass spectrometry (IRMS) identifies isotopedependent biological processes (see Reference 1 and references therein), measures elemental tracers (2), quantifies isotopically labeled compounds (3), and has recently been adapted for tracing biological pathways using multiple isotopic masses (4). Another form of IRMS was developed 25 years ago to directly count individual ions of very rare isotopes. Acceleration of the ions to million electron volt energies was the key to collisional destruction of any molecular isobars while supplying ions of sufficient energy for identifying the resulting atomic ions by their characteristic interactions with nuclear particle detectors. This accelerator mass spectrometry (AMS) is so sensitive that it is only used for isotopes having concentrations of parts per billion to parts per quintillion in the isolated elemental sample. The least abundant stable isotope, ${ }^{3} \mathrm{He}$, is present at 1.4 parts per million and was initially discovered in a type of AMS, but the present form of AMS was purposely developed to quantify long-lived radioisotopes, particularly ${ }^{14} \mathrm{C}$, at natural concentrations independently of their decay properties $(5,6)$. This article presents the AMS method and some of its benefits in preclinical applications, including how ADME and binding studies are advanced by the high sensitivity and precision for very low levels of isotope-labeled compounds.

AMS is now the essential technology for radiocarbon dates of small, precious, and/or especially old archaeological or earth science samples (7). The natural ${ }^{14} \mathrm{C}$ content in a milligram of carbon in equilibrium with the present biosphere, $105 \mathrm{amol}$, represents $<1$ decay per hour but is easily quantified to better than $1 \%$ precision in less than a minute with AMS. AMS can quantify the ${ }^{14} \mathrm{C}$ in $1 \mathrm{mg}$ or less of carbon that may be as much as 50,000 years old, corresponding to $<200 \mathrm{zmole}\left(10^{-21} \mathrm{~mol}\right)$ of the isotope. An upper limit of approximately $100 \mathrm{fmol}{ }^{14} \mathrm{C} / \mathrm{mg}$ carbon is set by counting limitations in the spectrometer. Radiocarbon dating drove the initial development of AMS and still dominates the use of the approximately 100 instruments in the world. The power of direct ion counting by AMS is even more important for longer lived isotopes that cannot be effectively quantified by decay counting. Some of these, especially ${ }^{41} \mathrm{Ca}$, also have significant biomedical applications (8). Isotopes with half-lives as short as 10 years are efficiently quantified by AMS, with AMS quantitation of tritium providing a gain of about 1000 in sample size and speed of measurement (9). This quantitative sensitivity for femtomole to zeptomole was finally applied to biological research in 1990 (10) and became available over the past 15 years through some established AMS facilities, from several new commercial laboratories, from in-house instruments, or from our National Institutes of Health $(\mathrm{NIH})$-funded Research Resource for Biomedical AMS. The general concept of AMS is easiest described in terms of radiocarbon, as is done here in reference to the specific spectrometers at Lawrence Livermore National Laboratory (LLNL), Livermore, $\mathrm{CA}$.

\section{AMS MEASUREMENT}

AMS is an isotope ratio MS that quantifies only a fraction of the presented sample, requiring the sample to be isotopically uniform over the period of measurement. A physically or chemically defined biological sample is first homogenized by combustion to $\mathrm{CO}_{2}$ as is done with other carbon IRMS measurements. Other isotope samples $(\mathrm{Cl}, \mathrm{Ca}$, etc.) may be homogenized in an acid solution prior to purification and precipitation to a solid sample form. Some ion sources accept the purified $\mathrm{CO}_{2}$ directly (11-13), but most facilities reduce the carbon sample to solid fullerene on an iron catalyst to obtain the most intense, efficient, and sensitive ionization of the sample (14-16). A cesium sputter ion source produces negative carbon ions from the elemental or gaseous sample. The key to early application of AMS to carbon is the inability of nitrogen to make a negative ion, effectively removing the atomic isobar of ${ }^{14} \mathrm{C}$ without resorting to any spectrometric or chemical methods (9). Very few other isotopes share this fortuitous circumstance; creative chemical preparation and ion identification schemes suppress their atomic isobars. For example, $\mathrm{CaF}_{3}{ }^{-}$ions are accelerated in measuring ${ }^{41} \mathrm{Ca}$, because the low production of triple halide ions of potassium suppresses the isobar, ${ }^{41} \mathrm{~K}(17)$.

The ions are selected by a simple dipole MS for mass 14 , but a background $10^{10}$ greater than ${ }^{14} \mathrm{C}$ comes from mass 14 molecules such as ${ }^{12} \mathrm{CH}_{2},{ }^{13} \mathrm{CH}, \mathrm{Li}_{2}$, etc., which are broken by a gas or thin solid in a collision cell held at high positive potential. Collisional destruction of carbon hydrides requires more than $2.5 \mathrm{MeV}$ collision energies to destroy all molecules in a single event (18). The highest efficiency for molecular destruction and positive carbon ion creation occurs around $6.5 \mathrm{MeV}$, producing a $70 \%$ yield of $\mathrm{C}^{4+}$ from C-. Our primary spectrometer can maintain the collision cell at voltages up

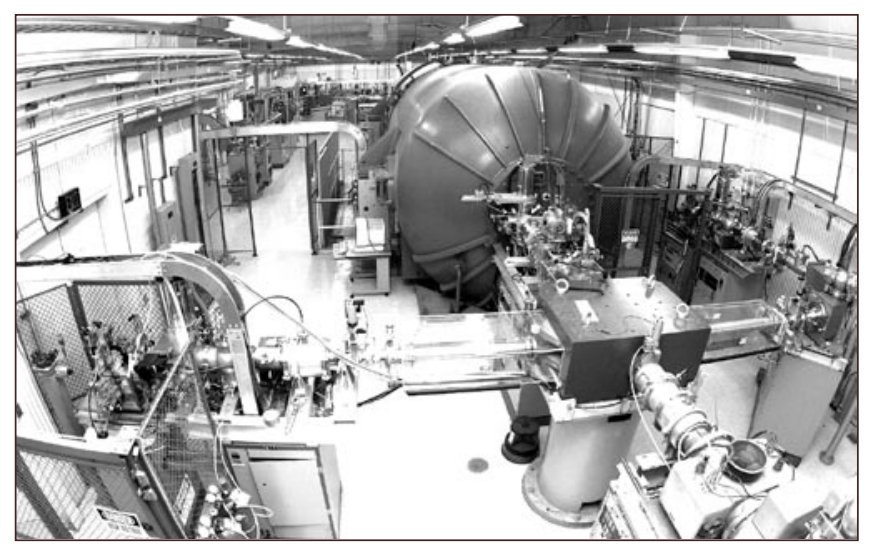

Figure 1. The $10 \mathrm{MV}$ accelerator mass spectrometry (AMS) at Lawrence Livermore National Laboratory (LLNL) has a very high-throughput and precision for ${ }^{14} \mathrm{C}$ analyses but is also a versatile spectrometer for quantifying specific isotopes from tritium to plutonium. 


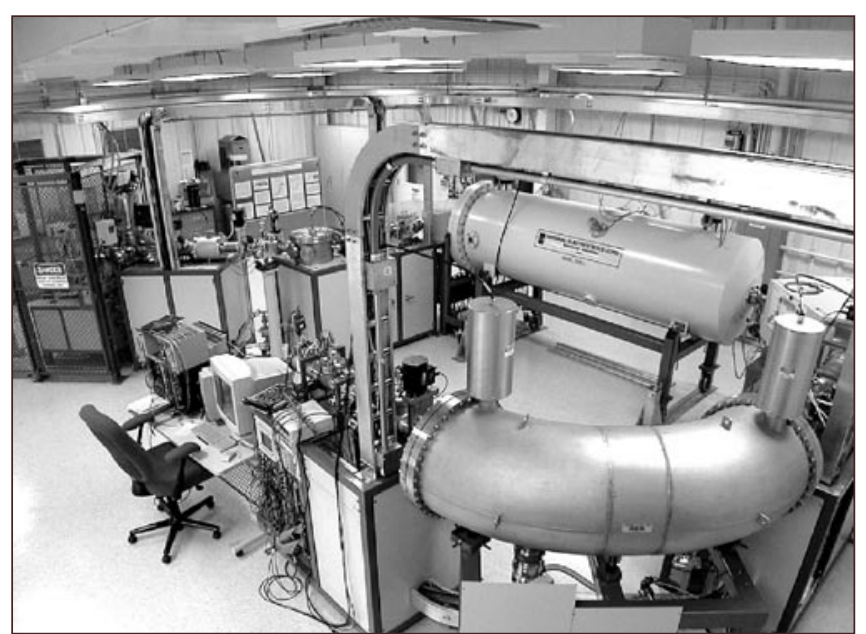

Figure 2. The $1 \mathrm{MV}$ spectrometer at Lawrence Livermore National Laboratory (LLNL) is operated at $0.5 \mathrm{MV}$ for biomedical ${ }^{14} \mathrm{C}$ measurements and is being modified for higher throughput of tritium samples.

to $10 \mathrm{MV}$. Insulation of this voltage requires a large surrounding vessel of insulating $\mathrm{SF}_{6}$ and ancillary equipment that can cause a spectrometer to fill a building (Figure 1). Newer, smaller spectrometers (Figure 2) use multiple ion collisions in a longer path through gas to destroy hydride molecules at potentials of $200 \mathrm{kV}$ or more $(19,20)$. The positive ions created in the collision accelerate away from the high positive potential. Multiple magnetic and/or electrostatic stages separate the hundreds of ${ }^{14} \mathrm{C}$ ions per second from the tens of microamps (1012 particles per second) of ions from the destroyed molecules. Finally, each ion is slowed to rest in a detector. This slowing depends on the ion's charge and mass in well-defined ways, making possible the identification of each ion for counting. These ion counts are normalized to a similarly accelerated beam of stable isotope ions from the sample (e.g., ${ }^{13} \mathrm{C}$ ), either in sequence or simultaneously (21). Samples of standard materials having well-known isotope concentrations are measured among the other samples for normalization.

The measured ${ }^{14} \mathrm{C} / \mathrm{C}$ ratio is often quoted in multiples of "Modern," a unit representing the natural level of biosphere ${ }^{14} \mathrm{C}$, had it not been disturbed by solar activity, fossil fuel burning, or atmospheric nuclear weapons tests in past decades. Modern is equivalent to $97.8 \mathrm{amol}$ ${ }^{14} \mathrm{C} / \mathrm{mg}$ carbon or $6.11 \mathrm{fCi}{ }^{14} \mathrm{C} / \mathrm{mg}$ carbon. The natural ${ }^{14} \mathrm{C}$ level in living plants and animals remains in excellent equilibrium with the atmospheric concentration (approximately 1.075 Modern in 2005), which is decreasing as the atmospheric test-related ${ }^{14} \mathrm{C}$ of the early $1960 \mathrm{~s}$ is dissolved into the oceans. The plasma of 53 women from various U.S. locations averaged $1.086 \pm 0.014$ Modern in early 2004 (average $\pm \mathrm{sD}$, Bradley Keck, personal communication), which is in excellent agreement with Northern hemisphere tree ring measurements (22). A measurement precision of $1 \%$ and the $1.3 \%$ variability in a population means that ${ }^{14} \mathrm{C}$ from labeled compounds can be quantified above natural background concentrations to about 6.5 amol/mg carbon ( $95 \%$ confidence level). The author has previously written a detailed discussion of the calculations for interpreting AMS ${ }^{14} \mathrm{C}$ data and planning AMS kinetic studies (23).

\section{AMS FOR ABSORPTION, DISTRIBUTION, METABOLISM, AND EXCRETION MEASUREMENTS}

AMS's high sensitivity and specificity provides pharmacokinetic (PK) profiles of small doses of isotope-labeled compounds in model animals, or directly in humans, using only small samples of excreta, fluid, or tissue. Any excess isotope above the well-known and measurable predose level is attributable to the compound or its derivatives, as long as accidental contamination of samples is well controlled. The lifetime radiative dose of a volunteer's isotope exposure for AMS tracing is often only a fraction of natural radiation levels, so that even children and special populations may be included in clinical studies.

Less than $1 \mathrm{mg}$ carbon is needed for AMS measurement, and this is available from $<20 \mu \mathrm{L}$ plasma. This small volume is available from an indwelling catheter or minor blood draw (e.g., finger prick or tail nick, depending on species) without disturbing the overall physiology. Even absorption phases of ingested compounds are easily measured in a rapid series of such draws. Some hydrophilic vitamins, like folate (Figure $3 \mathrm{~A}$ ), reveal gastric absorption by their rapid appearance in plasma (24), while lipophilic provitamins, such as $\beta$-carotene, clearly indicate the lipid intake due to lunch and dinner in Figure 3B (25). Absorption kinetics, whether by diffusion or transport, are measurable without saturation effects, because the chemical dose is comparable to physiological, environmental, or subpharmacological levels.

Long-term kinetic studies with AMS can extend up to months after an exposure, given the high sensitivity for the specific isotope label. Long-term retention of a compound arises from specific binding (26), lipid association (27), enterohepatic recirculation (24), or cellular uptake (28). This retention represents a neutral incorporation, an indicator of continued therapeutic effect, or a potential toxicity that requires further investigation. A cellularly retained compound is often quantifiable in the leukocytes or erythrocytes of $100 \mu \mathrm{L}$ blood, providing a minimally invasive measure of the compound's cellular kinetics or the cellular lifetimes, if the compound is retained by incorporation. Compartmental models based on the high data density available from AMS measurements of many small samples often suggest the physiological component driving the long-term kinetic profile (24). Retained fractions are measured precisely enough to set firm lower limits on compound clearance, well below those achievable with exhaustive mass balance measurements.

This sensitivity is also used to drastically reduce the chemical and radiative doses used in both preclinical animal studies and first-in-human tests of kinetic parameters at very low, presumably nontoxic, doses with radiative doses of a few nanoCuries (a few hundred becquerels). This application of AMS has been dubbed microdosing $(29,30)$ and is an important driver of AMS in drug development programs. Low-dose PK with AMS is especially important in the study of nutrients (24), receptor-mediated drugs that have

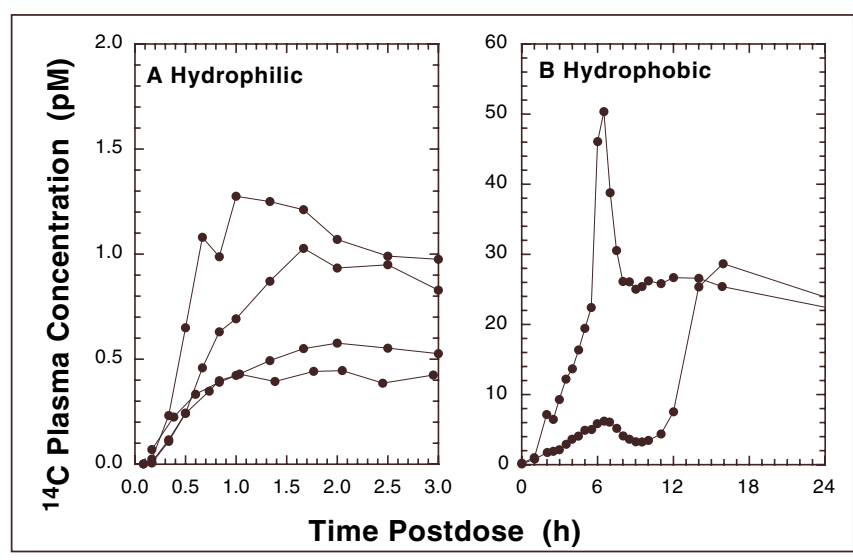

Figure 3. Measured absorption phases of ingested compounds. (A) The absorption phase of hydrophilic folate pharmacokinetics in plasma is shown for four human volunteers after ingestion of a 35- $\mu \mathrm{g} 100 \mathrm{nCi}$ dose of ${ }^{4} \mathrm{C}$-folate. (B) The slower and more complex absorption phase of lipophilic beta-carotene is seen in the plasma of two human volunteers after a 1-mg $200 \mathrm{nCi}$ ingested dose. 


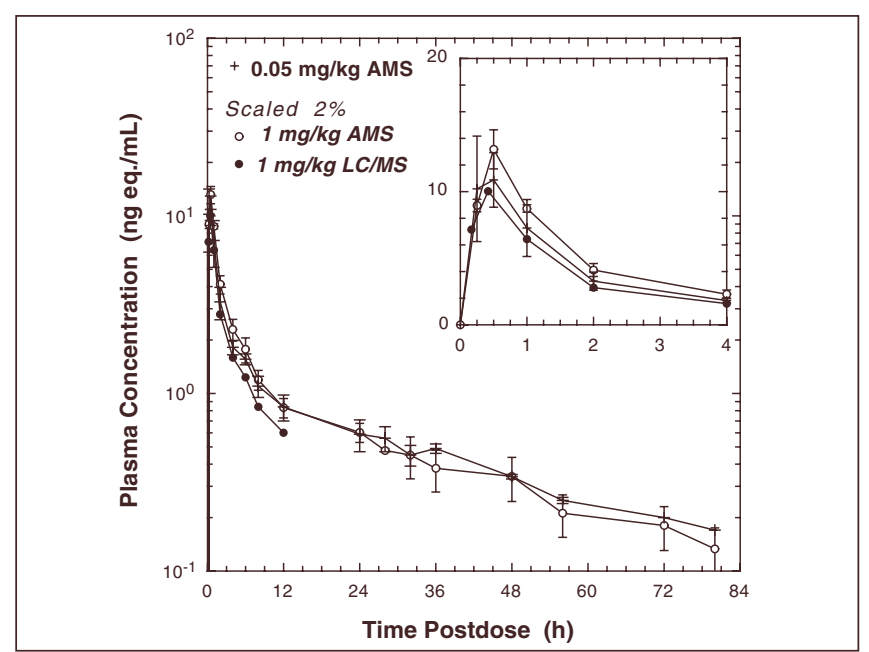

Figure 4. Plasma kinetics for the ${ }^{14} \mathrm{C}$ label of an adenosine analog show similar rapid clearance followed by a slower clearance at a mean rate of $0.05 / \mathrm{h}$ for oral exposures at a pharmacological dose and at $2 \%$ that dose. Liquid chromatography mass spectrometry (LC/MS) measurement of the parent compound at the higher dose was undetermined past $12 \mathrm{~h}$. AMS, accelerator mass spectrometry.

effects at physiologic concentrations, determining systemic PK of localized exposures of poorly distributed compounds or from implanted devices (31), and human studies of environmental or nontherapeutic chemical exposures $(10,32,33)$.

In one study, a nucleoside analog was found to have equivalent kinetics in dog with a therapeutic dose of $1 \mathrm{mg} / \mathrm{kg}$ as with a subtherapeutic dose of $0.02 \mathrm{mg} / \mathrm{kg}$ (34). This nucleosidic antiviral can be expected to have a retained cellular component (35). The plasma kinetics were unobtainable past $12 \mathrm{~h}$ using liquid chromatography tandem MS (LC/MS/MS), but the important signature of retention is not yet apparent in that plasma data. AMS obtained a precise measure of the long-term plasma concentration due to the compound's return from cellular pools over a period of 3 days postdose using the lower exposure (Figure 4). The LC/MS data for the parent compound remain lower $(65 \%-80 \%)$ than the AMS data through their common range, because unfractionated plasma was used for the AMS measurements of the isotope label on the parent and all metabolic or bound fractions. LC/AMS has been used to trace the 6-month kinetics of labeled $\beta$-carotene and its metabolites in human plasma, demonstrating that parent concentrations of a dose can also be quantified with AMS sensitivity after suitable metabolite separations (25).

\section{LC/AMS METABOLIC PROFILES}

There are only a few human metabolites of $\beta$-carotene, including the important vitamin A products, but even this well-studied compound revealed unexpected, admittedly minor, metabolites in LC/AMS separations (27). Isotope labeling is the preferred method for discovering and quantifying the relative yields of metabolites in vivo. AMS produces unambiguous metabolic profiles of the dosed labeled compound to femtomolar concentrations with precise relative abundances without resorting to internal standards. Unlabeled standards may be added to the sample prior to chromatography to aide in separations of very small samples and/or to assist in determining times for fraction collection without affecting the quantitation. Quantitative metabolic profiles in plasma or urine are obtained by comparing the isotopic concentration of the injected sample with the sum of the eluted isotope profile to correct for any analytical losses. Several different components add to the backgrounds of LC/AMS,

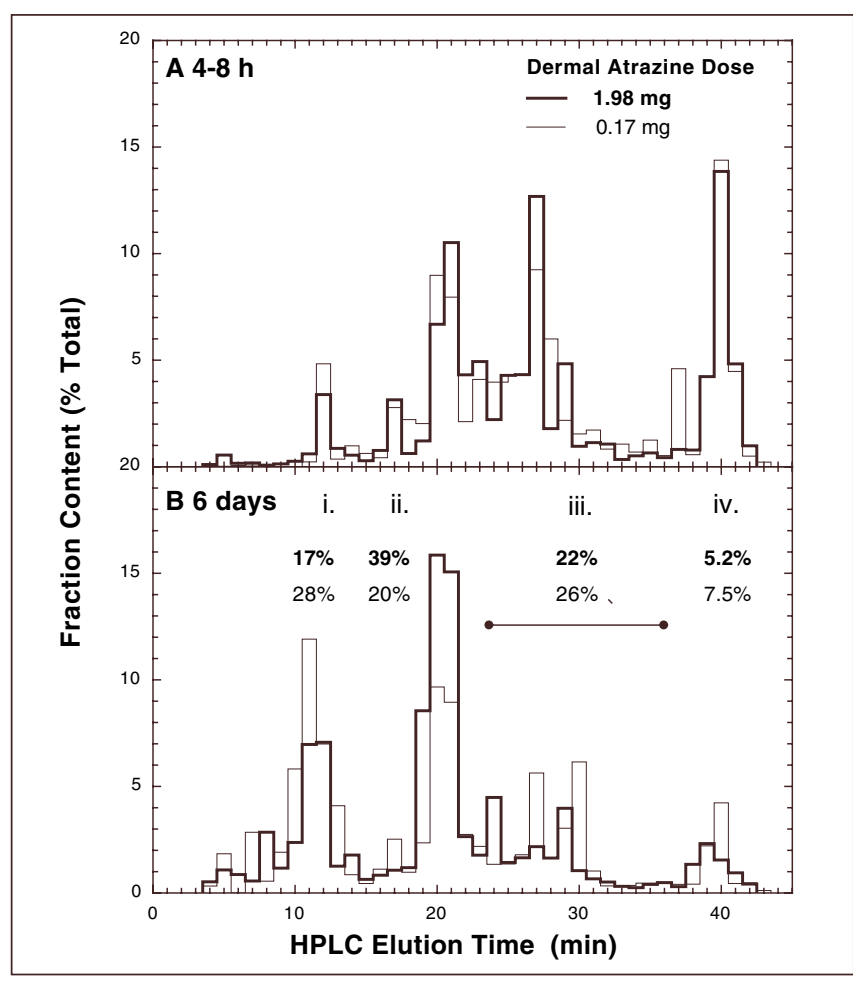

Figure 5. Human metabolites of dermally applied atrazine are shown as HPLC traces of urine expressed as a percentage of eluted label for (A) 4-8 $h$ postdose and (B) 6 days postdose at two doses differing by a factor of 10 . Both doses have a significant, previously unknown, polar metabolite (i) at $11 \mathrm{~min}$, as well as primary metabolites of didealkyl atrazine and their mercapturates (ii). The low dose may favor more monodealkyl atrazine metabolites (iii). Both show atrazine mercapturate (iv). HPLC, highperformance liquid chromatography.

and total column loading should be held under $10 \mathrm{fmol}$ total ${ }^{14} \mathrm{C}$ [1 disintegration per minute (dpm)] to avoid valve or column contaminations in succeeding analyses (36). Simple fraction collection can be used to obtain the kinetics of the separate species, if there are only a few established metabolites as with carotene metabolism, but even low resolution $(1 \mathrm{~min}$ ) fractions often reveal sufficient detail to determine changes in major metabolites and the presence of previously unnoticed products.

Atrazine metabolites in human urine were quantified during, and for several days after, dermal exposures (37). Metabolite profiles differed little in urines taken during the day-long dermal exposure (Figure $5 \mathrm{~A}$ ), but by 5 days postexposure, some preference toward doubly dealkylated metabolites was appearing in the high-dosed subjects. The purpose of the study was to determine the metabolite that is the best marker of human exposure to atrazine, and it was concluded that the didealkyl atrazine and its mercapturate were the suitable targets. Figure 5 normalizes the chromatograms as percents of total elution signal, which represented $7.8 \mathrm{pg}$ atrazineequivalents in the high-dose trace and only $2.6 \mathrm{pg}$ in the low-dose trace. Analytical error bars at $<0.1 \%$ were left off Figure 5 for clarity. Metabolites as low as $1 \%$ of the total can be measured. Clearly, analytical sensitivity is sufficient for shorter fraction collections that would better distinguish the specific mono- and didealkylated species, if desired. Unlabeled standard compounds were available to identify labeled species through coelution. There are active programs in ours and other laboratories to directly link separatory instruments to AMS $(38,39)$, so that continuous LC analysis of metabolism will be possible for more general metabolic profiles. 


\section{AMS IN BINDING}

Human PK had been the single most difficult hurdle for candidate compounds that survived through development up to first-in-human studies, but toxicology and efficacy have become the leading causes of rejecting candidates in recent years (40). Toxicity and efficacy are related to the tissue distribution and biomolecular targets of a dosed compound. Again, AMS sensitivity and specificity for an isotopic label reveal distribution and binding in vivo without saturation effects. The first uses of ${ }^{14} \mathrm{C}$-AMS in biochemistry quantified chemical genotoxicity by measuring DNA adducted compounds in animals $(10,41)$. The protein component of genotoxicity was also assessed for benzene at environmental dose levels (42). Human studies of low-level adducts depended on surgical sample collection (43), but human/rodent assays for circulating protein adducts showed a direction for less invasive monitoring of compound activation by human metabolism using only a few milliliters of blood (44). The sophistication of protein separation prior to AMS quantitation determines the experimental resolution.

In one study, we found the murine distribution and targets of diisopropylfluorophosphate (DFP), an anticholinesterase drug as well as an analog of more potent nerve agents. The PK of subtoxic doses of ${ }^{14} \mathrm{C}$-DFP (1 $\mu \mathrm{g} / \mathrm{kg}$, by mouth) in plasma, red blood cells (RBCs), and brain tissue revealed a very rapid clearance of the parent and metabolites, followed by the slow loss of the bound fractions (26). The plasma-linked ${ }^{14} \mathrm{C}$ signal had a mean life in good agreement with the lifetime of plasma proteins in mice. RBC-bound DFP was also consistent with the longer expected RBC lifetime. The brain-bound isotope signal was consistent with little or no target turnover during the 1 week after dosing. We expected that a number of plasma esterases/hydrolases might be targeted by the very active fluorine in DFP. We separated plasma proteins on isoelectric focusing (IEF) strips at various times postdose. We were surprised to find only one major target and one minor group of proteins that were bound to DFP at both 1 and $48 \mathrm{~h}$ postdose, although the major target was different at the two times. Figure $6 \mathrm{~A}$ shows the AMS quantitation of a sample of mouse plasma from $1 \mathrm{~h}$ after DFP

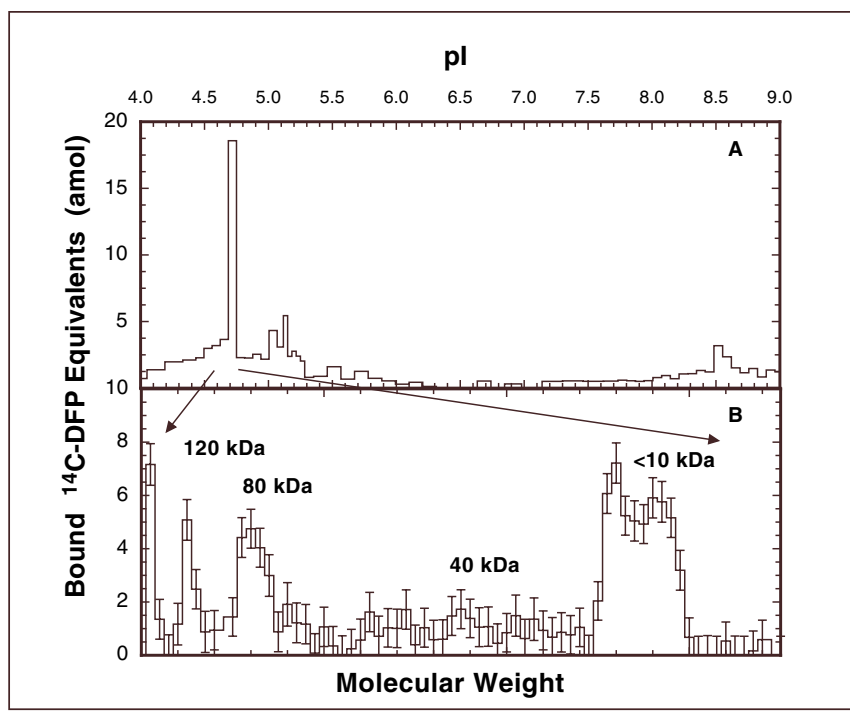

Figure 6. Plasma protein targets of binding are separated by isoelectric and molecular weight gels for AMS quantitation. Mouse plasma proteins were separated on an isoelectric (pI) focusing strip (A) from a sample taken $1 \mathrm{~h}$ after dosing with diisopropylfluorophosphate (DFP). The peak of bound label at $4.7 \mathrm{pI}$ was further separated for molecular weight on polyacrylamide gel electrophoresis (PAGE) (B) to find that the protein binding was consistent with the dimer and trimer of paraoxonase. The sub-10-kDa signal is attributed to glutathione detoxification of the reactive compound. exposure spread on an IEF strip from $\mathrm{pH}$ 4.0-9.0. Figure $6 \mathrm{~B}$ shows a background-corrected AMS quantitation of the sodium dodecyl sulfate polyacrylamide gel electrophoresis (SDS-PAGE) separation of molecular weights for the piece of the IEF strip from 4.5 to 4.8 . The majority of the ${ }^{14} \mathrm{C}$ moved with the dye front to below $10 \mathrm{kDa}$ molecular weight. Little or no signal is seen below that broad peak. We suspect that this represents a complex of DFP with glutathione during the rapid detoxification in the first hour after exposure. The two peaks at 80 and $120 \mathrm{kDa}$ are consistent with the isoelectric (pl) and weights of the dimer and trimer form of paraoxonase, with an insignificant suggestion of the monomer at a 1 amol level (45). Our attributions for these peaks have not yet been confirmed.

\section{CONCLUSION}

AMS quantification of separated biomolecular species provides high sensitivity and specificity for following the kinetics and dynamics of drug candidates at very low chemical or radiative exposure, opening the way to studies of: (i) extremely potent receptor-binding therapeutics; (ii) nontoxic doses of candidate compounds for early first-in-human tests; and (iii) human metabolism and protein binding using minimally invasive blood or needle biopsy draws. The high efficiency of AMS means that highly specific rare isotopes, such as ${ }^{14} \mathrm{C}$, can be used safely and efficiently in preclinical trials, including children, target populations, and women of child-bearing age. AMS is merely a quantitative tool, however, and the effectiveness of its use depends on the careful biological and chemical definition of the sample being quantified. If AMS were only a much more efficient way of measuring ${ }^{14} \mathrm{C}$, its value might lie in reduction of radioactive waste, lessening of labeling requirements in chemical synthesis, or lower radiative exposure to experimenters and volunteers. These are indeed benefits of AMS quantitation, but the real power of the method for drug discovery lies in the human data that it empowers early in a drug development program. It is a safe tool to get data from populations that are of most concern in dosing, efficacy, and toxicity.

\section{ACKNOWLEDGMENTS}

This work was performed in part under the auspices of the U.S. Department of Energy by University of California Lawrence Livermore National Laboratory under contract no. W-7405-Eng-48 and funded by the NIH National Center for Research Resources (NCRR) for Biomedical AMS, P41-RR013641.

\section{COMPETING INTERESTS STATEMENT}

The author declares no competing interests.

\section{REFERENCES}

1.Cleland, W.W. 2005. The use of isotope effects to determine enzyme mechanisms. Arch. Biochem. Biophys. 433:2-12.

2. Sturup, S. 2004. The use of ICPMS for stable isotope tracer studies in humans: a review. Anal. Bioanal. Chem. 378:273-282.

3. Blair, I.A. and A. Tilve. 2002. Analysis of anticancer drugs and their metabolites by mass spectrometry. Curr. Drug Metab. 3:463-480.

4. Turner, S.M. and M.K. Hellerstein. 2005. Emerging applications of kinetic biomarkers in preclinical and clinical drug development. Curr. Opin. Drug Discov. Devel. 8:115-126.

5. Nelson, D.E., R.G. Korteling, and W.R. Stott. 1977. Carbon-14: direct detection at natural concentrations. Science 198:507-508.

6. Bennett, C.L., R.P. Beukens, M.R. Clover, H.E. Gove, R.B. Liebert, A.E. Litherland, K.H. Purser, and W.E. Sondheim. 1977. Radiocarbon dating using electrostatic accelerators: negative-ions provide key. Science 198:508-510.

7. Guilderson, T.P., P.J. Reimer, and T.A. Brown. 2005. Geoscience. The boon and bane of radiocarbon dating. Science 307:362-364.

8. Lin, Y., D.J. Hillegonds, E.R. Gertz, M.D. Van Loan, and J.S. Vogel. 2004. Protocol for assessing bone health in humans by tracing long-lived 41Ca isotope in urine, serum, and saliva samples. Anal. Biochem. 332:193-195. 
9. Chiarappa-Zucca, M.L., K.H. Dingley, M.L. Roberts, C.A. Velsko, and A.H. Love. 2002. Sample preparation for quantitation of tritium by accelerator mass spectrometry. Anal. Chem. 74:6285-6290.

10. Turteltaub, K.W., J.S. Felton, B.L. Gledhill, J.S. Vogel, J.R. Southon, M.W. Caffee, R.C. Finkel, D.E. Nelson, et al. 1990. Accelerator mass spectrometry in biomedical dosimetry: relationship between low-level exposure and covalent binding of heterocyclic amine carcinogens to DNA. Proc. Natl. Acad. Sci. USA 87:5288-5292

11. Middleton, R. 1984. A review of ion sources for accelerator mass spectrometry. Nucl. Instrum. Methods Phys. Res. B B233:193-199.

12. Bronk, C. and R.E.M. Hedges. 1990. A gaseous ion source for routine AMS radiocarbon dating. Nucl. Instrum. Methods Phys. Res. B B52:322-326.

13. Shibata, Y., H. Kume, A. Tanaka, M. Yoneda, Y. Kumamoto, T. Uehiro, and M. Morita. 1997. A preliminary report on the characteristics of a $\mathrm{CO}_{2}$-gas ion source MGF-SNICS at NIES-TERRA. Nucl. Instrum. Methods Phys. Res. B B123:554557.

14. Vogel, J.S., J.R. Southon, D.E. Nelson, and T.A. Brown. 1984. Performance of catalytically condensed carbon for use in accelerator mass spectrometry. Nucl. Instrum. Methods B5:289-293

15. Vogel, J.S. 1992. Rapid production of graphite without contamination for biomedical AMS. Radiocarbon 34:344-350

16. Ognibene, T.J., G. Bench, J.S. Vogel, G.F. Peaslee, and S. Murov. 2003. A high-throughput method for the conversion of $\mathrm{CO}_{2}$ obtained from biochemical samples to graphite in septa-sealed vials for quantification of ${ }^{14} \mathrm{C}$ via accelerator mass spectrometry. Anal. Chem. 75:2192-2196.

17.Freeman, S.P.H.T., R.E. Serfass, J.C. King, J.R. Southon, Y. Fang, L.R. Woodhouse, G.S. Bench, and J.E. McAninch. 1995. Biological sample preparation and 41-Ca AMS measurement at LLNL. Nucl. Instrum. Methods Phys. Res. B B99:557-561.

18. Lee, H.W., A. Galindo-Uribarri, K.H. Chang, L.R. Kilius, and A.E. Litherland. 1984. The ${ }^{12} \mathrm{CH}_{2}{ }^{2+}-$ molecule and radiocarbon dating by accelerator mass spectrometry. Nucl. Instrum. Methods Phys. Res. B B233:208-210.

19. Suter, M., S. Jacob, and H.A. Synal. 1997. AMS of 14-C at low energies. Nucl. Instrum. Methods Phys. Res. B B123:148-152.

20. Hughey, B.J., R.E. Shefer, R.E. Klinkowstein, X.L. Zhao, W.E. Kieser, and A.E. Litherland. 1997. Experimental investigation of the destruction of $1 \mathrm{MeV}$ ${ }^{12} \mathrm{CH}_{2}$-molecules in single and double stripping foils. Nucl. Instrum. Methods Phys. Res. B B123:186-192.

21.Southon, J.R., D.E. Nelson, and J.S. Vogel. 1990. Injection systems for AMS: simultaneous versus sequential. Nucl. Instrum. Methods Phys. Res. B B52:370-374

22. Kromer, B., S.W. Manning, P.I. Kuniholm, M.W. Newton, M. Spurk, and I. Levin. 2001. Regional ${ }^{14} \mathrm{CO}_{2}$ offsets in the troposphere: magnitude, mechanisms, and consequences. Science 294:2529-2532.

23. Vogel, J.S. and A.H. Love. 2005. Quantitating isotopic molecular labels with accelerator mass spectrometry. In A.L. Burlingame (Ed.), Methods in Enzymology. Academic Press, San Diego.

24. Lin, Y., S.R. Dueker, J.R. Follett, J.G. Fadel, A. Arjomand, P.D. Schneider, J.W. Miller, R. Green, et al. 2004. Quantitation of in vivo human folate metabolism. Am. J. Clin. Nutr. 80:680-691.

25. Lemke, S.L., S.R. Dueker, J.R. Follett, Y. Lin, C. Carkeet, B.A. Buchholz, J.S. Vogel, and A.J. Clifford. 2003. Absorption and retinol equivalence of betacarotene in humans is influenced by dietary vitamin A intake. J. Lipid Res. 44:1591-1600.

26. Vogel, J.S., G.A. Keating 2nd, and B.A. Buchholz. 2002. Protein binding of isofluorophate in vivo after coexposure to multiple chemicals. Environ. Health Perspect. 110(Suppl 6):1031-1036.

27. Dueker, S.R., Y. Lin, B.A. Buchholz, P.D. Schneider, M.W. Lame, H.J. Segall, J.S. Vogel, and A.J. Clifford. 2000. Long-term kinetic study of betacarotene, using accelerator mass spectrometry in an adult volunteer. J. Lipid Res. 41:1790-1800

28. Buchholz, B.A., A. Arjomand, S.R. Dueker, P.D. Schneider, A.J. Clifford, and J.S. Vogel. 1999. Intrinsic erythrocyte labeling and attomole pharmacokinetic tracing of ${ }^{14} \mathrm{C}$-labeled folic acid with accelerator mass spectrometry. Anal. Biochem. 269:348-352.

29. Combes, R.D., T. Berridge, J. Connelly, M.D. Eve, R.C. Garner, S. Toon, and P. Wilcox. 2003. Early microdose drug studies in human volunteers can minimise animal testing: proceedings of a workshop organised by Volunteers in Research and Testing. Eur. J. Pharm. Sci. 19:1-11.
30. Lappin, G. and R.C. Garner. 2003. Big physics, small doses: the use of AMS and PET in human microdosing of development drugs. Nat. Rev. Drug Discov. 2:233-240.

31. Li, Y., R.S. Shawgo, B. Tyler, P.T. Henderson, J.S. Vogel, A. Rosenberg, P.B. Storm, R. Langer, et al. 2004. In vivo release from a drug delivery MEMS device. J. Control Release 100:211-219.

32. Creek, M.R., C. Mani, J.S. Vogel, and K.W. Turteltaub. 1997. Tissue distribution and macromolecular binding of extremely low doses of $\left[{ }^{14} \mathrm{C}\right]$-benzene in B6C3F1 mice. Carcinogenesis 18:2421-2427.

33. Mauthe, R.J., K.H. Dingley, S.H. Leveson, S.P. Freeman, R.J. Turesky, R.C. Garner, and K.W. Turteltaub. 1999. Comparison of DNA-adduct and tissueavailable dose levels of MelQx in human and rodent colon following administration of a very low dose. Int. J. Cancer 80:539-545

34. Sandhu, P., J.S. Vogel, M.J. Rose, E.A. Ubick, J.E. Brunner, M.A. Wallace, J.K. Adelsberger, M.P. Baker, et al. 2004. Evaluation of microdosing strategies for studies in preclinical drug development: demonstration of linear pharmacokinetics in dogs of a nucleoside analog over a 50 -fold dose range. Drug Metab. Dispos. 32:1254-1259.

35. Olsen, D.B., A.B. Eldrup, L. Bartholomew, B. Bhat, M.R. Bosserman, A. Ceccacci, L.F. Colwell, J.F. Fay, et al. 2004. A 7-deaza-adenosine analog is a potent and selective inhibitor of hepatitis $C$ virus replication with excellent pharmacokinetic properties. Antimicrob. Agents Chemother. 48:3944-3953.

36. Creek, M.R., C.E. Frantz, E. Fultz, K. Haack, K. Redwine, N. Shen, K.W. Turteltaub, and J.S. Vogel. 1994. ${ }^{14} \mathrm{C}$ AMS quantification of biomolecular interactions using microbore and plate separations. Nucl. Instrum. Methods B92:454-458

37. Buchholz, B.A., E. Fultz, K.W. Haack, J.S. Vogel, S.D. Gilman, S.J. Gee, B.D. Hammock, X. Hui, et al. 1999. HPLC-accelerator MS measurement of atrazine metabolites in human urine after dermal exposure. Anal. Chem. 71:3519-3525.

38.Liberman, R.G., S.R. Tannenbaum, B.J. Hughey, R.E. Shefer, R.E. Klinkowstein, C. Prakash, S.P. Harriman, and P.L. Skipper. 2004. An interface for direct analysis of (14)C in nonvolatile samples by accelerator mass spectrometry. Anal. Chem. 76:328-334.

39.Choi, M.H., P.L. Skipper, J.S. Wishnok, and S.R. Tannenbaum. 2005 Characterization of testosterone 11\{beta\}-hydroxylation catalyzed by humanliver microsomal cytochromes P450. Drug Metab. Dispos. [Epub ahead of print, March 11, 2005]

40. Kola, I. and J. Landis. 2004. Can the pharmaceutical industry reduce attrition rates? Nat. Rev. Drug Discov. 3:711-715.

41. Frantz, C.E., C. Bangerter, E. Fultz, K.M. Mayer, J.S. Vogel, and K.W. Turteltaub. 1995. Dose-response studies of MelQx in rat-liver and liver DNA at low-doses. Carcinogenesis 16:367-373.

42. Williams, K.E., T.A. Carver, J.J. Miranda, A. Kautiainen, J.S. Vogel, K. Dingley, M.A. Baldwin, K.W. Turteltaub, and A.L. Burlingame. 2002. Attomole detection of in vivo protein targets of benzene in mice: evidence for a highly reactive metabolite. Mol. Cell. Proteomics 1:885-895.

43. Turteltaub, K.W., R.J. Mauthe, K.H. Dingley, J.S. Vogel, C.E. Frantz, R.C. Garner, and N. Shen. 1997. MelQx-DNA adduct formation in rodent and human tissues at low doses. Mutat. Res. 376:243-252.

44. Dingley, K.H., S. Freeman, D.O. Nelson, R.C. Garner, and K.W. Turteltaub. 1998. Covalent binding of 2-amino-3,8-dimethylimidazo[4,5-f]quinoxaline to albumin and hemoglobin at environmentally relevant doses-comparison of human subjects and F344 rats. Drug Metab. Dispos. 26:825-828.

45. Josse, D., C. Ebel, D. Stroebel, A. Fontaine, F. Borges, A. Echalier, D. Baud F. Renault, et al. 2002. Oligomeric states of the detergent-solubilized human serum paraoxonase (PON1). J. Biol. Chem. 277:33386-33397.

Address correspondence to:

John S. Vogel

University of California

Lawrence Livermore National Laboratory

7000 East Avenue, L-397

Livermore CA 94551, USA

e-mail: jsvogel@IInl.gov 